\title{
Fructose Drives Glucose via Direct Oxidation and Promotes Palmitate/ Oleate Co-Release from Hepg2 Cells: Relevance with the Randle Cycle
}

László G Boros ${ }^{1,2}$, Danshan Huang ${ }^{3}$ and Anthony P Heaney ${ }^{3,4 *}$

${ }^{1}$ Harbor-UCLA Medical Center Department of Pediatrics, Torrance, CA, USA

${ }^{2}$ SiDMAP, LLC, CA, USA

${ }^{3}$ Departments of Medicine David Geffen School of Medicine at UCLA, California, USA

${ }^{4}$ Departments of Neurosurgery David Geffen School of Medicine at UCLA, California, USA

\begin{abstract}
Background \& methods: Evidence indicates that there are significant differences in how glucose and fructose affect host metabolism although the details remain unclear. We determined how liver cells adopt intermediary metabolism to fructose administration. Cultured HepG2 cells were incubated with $5 \mathrm{mM}$ glucose or fructose, above the $5 \mathrm{mM}$ glucose concentration in control cultures. $\left[1,2-{ }^{13} \mathrm{C}_{2}\right]$-D-glucose was used as the single metabolic tracer.
\end{abstract}

Results: Addition of $5 \mathrm{mM}$ glucose maintained the ratio of complete glucose oxidation to that of other acetateyielding substrates, while addition of $5 \mathrm{mM}$ added fructose significantly decreased ${ }^{13} \mathrm{CO}_{2}$ Delta by its contribution to citrate and glutamate in the TCA cycle. Fructose maintained a high rate of direct glucose oxidation via G6PDH which was also seen with glucose-treatment. New palmitate production via fatty acid synthase was significantly increased by both sugars. In contrast to glucose-treatment which resulted in increased intracellular palmitate and oleate content, fructose increased the co-release of newly formed palmitate and oleate into the culture media.

Conclusion: These findings demonstrate that fructose rearranges TCA cycle metabolism by providing acetylCoA for oxidation, increasing citrate shuttling and strongly promoting triglyceride efflux of altered de novo synthesis pathways.

Keywords: Fructose; Triglyceride; Metabolic syndrome; Randle cycle

\section{Introduction}

Although clinical evidence indicates that there are significant differences in how glucose and fructose affect host metabolism [1], the cellular mechanisms addressing specific steps of intermediary metabolism in liver cells have not yet been elucidated [2]. Recent developments in tracer substrate based metabolomics demonstrate that the $\left[1,2-{ }^{13} \mathrm{C}_{2}\right]$-D-glucose tracer offers precise in vitro characterization of pentose cycle, glycolysis and TCA cycle flux [3], as well as analysis of de novo (new) fatty acid synthesis, turnover and modifications (via chain shortening or elongation) in cell pellets, plasma or tissues [4]. Processed nutritional products account for $80 \%$ of human refined carbohydrate intake. As the disaccharide sucrose (50\% glucose, and $50 \%$ fructose) and high fructose corn syrup (HFCS, $45 \%$ glucose, and 55\% fructose) are the main dietary sugars, we designed a tracer substrate-based metabolic study to characterize and compare product synthesis and related intermediary and/ or adaptive events in hepatoma cells following addition of $5 \mathrm{mM}$ glucose or fructose to a base line (5 $\mathrm{mM})$ glucose supply in the culture media.

Our findings indicate that hepatoma cells readily utilize fructose with significant differences in intermediary metabolism and product synthesis compared to glucose, even when fructose is provided at equivalent rates to glucose [5]. Fructose is also a potent inducer of transketolase flux via the non-oxidative pentose phosphate pathway to generate nucleic acid ribose as we have previously described [6]. Additionally, fructose enters the TCA cycle and of most significance, unlike glucose, it promotes new palmitate and oleate synthesis and their co-release into the culture media.

\section{Methods}

\section{Cells}

The human hepatoma HepG2 cell line was obtained from ATCC
(HB-8065, American Type Culture Collection, and Manassas, Virginia) and cultured according to the manufacturer's instructions. Tumor cells were seeded in 6 well dishes, before incubation in standard DMEM media with $10 \%$ fetal bovine serum, and a range of glucose, or fructose concentrations for a total of $72 \mathrm{~h}$ with fresh media supplied at $24 \mathrm{~h}$ intervals.

\section{Metabolomic studies}

Three $(n=3) 75 \%$ confluent cultures of HepG2 $\left(3 \times 10^{6}\right)$ cells were incubated for 72 hours in either $0.5 \mathrm{mM}\left[1,2-{ }^{13} \mathrm{C}_{2}\right] \mathrm{D}$-glucose ( $>99 \%$ purity, and $99 \%$ isotope enrichment for each carbon position) (Cambridge Isotope Labs, Massachusetts) with $4.5 \mathrm{mM}$ natural labeled glucose alone (a total $5 \mathrm{mM}$ glucose; control), or with added $5 \mathrm{mM}$ glucose (a total of $10 \mathrm{mM}$ glucose, added glucose group) or added $5 \mathrm{mM}$ fructose (a total of $5 \mathrm{mM}$ glucose and $5 \mathrm{mM}$ fructose, added fructose group). In this experimental paradigm when $10 \%$ labeled glucose $\left(0.5 \mathrm{mM}\left[1,2-{ }^{13} \mathrm{C}_{2}\right] \mathrm{D}\right.$-glucose $)$ is added to the base line glucose concentration ( $4.5 \mathrm{mM}$ glucose), the ${ }^{13} \mathrm{C}$ glucose becomes the single tracer of intermediary metabolism by its positional ${ }^{13} \mathrm{C}$ carbon contributions to product synthesis. Following glucose- or fructosetreatments, culture medium $(2 \mathrm{ml})$ was collected, cells were washed

*Corresponding author: Anthony $P$ Heaney, Departments of Medicine \& Neurosurgery, David Geffen School of Medicine at UCLA, California, USA, E-mail: aheaney@mednet.ucla.edu

Received February 07, 2012; Accepted March 03, 2012; Published March 05, 2012

Citation: Boros LG, Huang D, Heaney AP (2012) Fructose Drives Glucose via Direct Oxidation and Promotes Palmitate/Oleate Co-Release from Hepg2 Cells: Relevance with the Randle Cycle. Metabolomics 2:107. doi:10.4172/21530769.1000107

Copyright: @ 2012 Boros LG, et al. This is an open-access article distributed under the terms of the Creative Commons Attribution License, which permits unrestricted use, distribution, and reproduction in any medium, provided the original author and source are credited. 
twice in PBS, after which cell pellets were harvested using 5\% Trypsin solution. Specific extractions were performed as described below and mass spectral data then obtained on a HP5975N mass selective detector connected to an HP6890N gas chromatograph. An Agilent J\&W HP5MS (30 m x $0.25 \mathrm{mM}$ x $0.25 \mu \mathrm{m}$; part \#: 19091S-433) analytical column was used for glucose, ribose, glutamate, and lactate analyses. For fatty acids and $\mathrm{CO}_{2}$ analysis an Agilent J\&W Scientific DB-23 (60 m x 0.25 $\mathrm{mM} \times 0.15 \mu \mathrm{m}$; part \#: 122-2361) column was used. Helium (>99.99\% purity) was used as the carrier gas in the electron impact ionization (EI) mode or methane ( $>99.99 \%$ purity, Praxair, Los Angeles, CA) in the chemical ionization (CI) mode were used, respectively. Sample injections were performed using 100 split ratios directly into the heated $\left(250^{\circ} \mathrm{C}\right)$ and pressurized inlet interfaces. Lactate was extracted from cell culture media $(0.2 \mathrm{ml})$ by ethylene chloride after acidification with HCL, derivatized to its propylamine-heptafluorobutyrate ester form and applied to the column. The $\mathrm{m} / \mathrm{z} 328$ (carbons 1-3 of lactate) (chemical ionization, CI) were monitored for the detection of $\mathrm{m}_{1}$ (recycled lactate through the PC), $\mathrm{m}_{2}$ (lactate produced by the EmbdenMeyerhof-Parnas pathway) $m_{3}$ (lactate produced by triose cycling) for the estimation of pentose cycle activity [7]. For analysis of fatty acid synthesis, palmitate, and oleate were extracted after saponification of cell pellets in $30 \% \mathrm{KOH}$ and $100 \%$ ethanol using petroleum ether. Fatty acids were then converted to their methylated derivative using $0.5 \mathrm{~N}$ methanolic-HCL, and palmitate and oleate were monitored at $\mathrm{m} / \mathrm{z} 270$, and $\mathrm{m} / \mathrm{z} 264$, respectively, for enrichment of glucose derived ${ }^{13} \mathrm{C}$ labeled acetyl units to reflect synthesis, elongation and desaturation of the new lipid fraction as determined by mass isotopomer distribution analysis (MIDA) $[7,8]$. To characterize the pentose cycle's operation for nucleic acid ribose synthesis, RNA ribose was isolated by acid hydrolysis of cellular RNA after Trizol purification of cell extracts. Ribose was then derivatized to its aldonitrile acetate form using hydroxylamine in pyridine with acetic anhydride (Supelco, Bellefonte, PA) before mass spectral analyses. The ion cluster was monitored around the $\mathrm{m} / \mathrm{z} 217$ (carbons 3-5 of ribose) and $\mathrm{m} / \mathrm{z} 242$ (carbons 1-4 of ribose) (electron impact ionization, EI) to determine molar enrichment and the positional distribution of ${ }^{13} \mathrm{C}$ in ribose. Ribose molecules labeled with a single ${ }^{13} \mathrm{C}$ atom on the first carbon position $\left(\mathrm{m} / \mathrm{z} 242 \mathrm{C}_{1}-\mathrm{C}_{4}\right.$ fragment; $M_{+1}$ ) recovered from RNA were used to gauge the ribose fraction produced by direct oxidation of glucose or fructose through the G6PDH pathway [5,9]. Ribose molecules labeled with ${ }^{13} \mathrm{C}$ on the first two carbon positions ( $\mathrm{m} / \mathrm{z} 242 \mathrm{C}_{1}-\mathrm{C}_{4}$ fragment; $\mathrm{M}_{+2}$ ) were used to measure the fraction produced by transketolase [10]. Doubly labeled ribose molecules $\left(\mathrm{m} / \mathrm{z} 217 \mathrm{C}_{3}-\mathrm{C}_{5}\right.$ fragment; $\left.\mathrm{M}_{+2}\right)$ on the fourth and fifth carbon positions were used to measure molar fraction produced by triose recycling via triose phosphate isomerase and transketolase for nucleotide synthesis.

Complete glucose oxidation to ${ }^{13} \mathrm{CO}_{2}$ analyses were performed from $100 \mu \mathrm{L}$ media sample in a GC vial by added $50 \mu \mathrm{L}$ of $0.1 \mathrm{M} \mathrm{NaHCO}_{3}$. Then $50 \mu \mathrm{L}$ of $1 \mathrm{M}$ HCL was added. The vials were immediately capped and placed on the GC/MS sample tray for analysis at the $\mathrm{m} / \mathrm{z} 44$ and $\mathrm{m} / \mathrm{z} 45$ ion groups [11]. Glutamate was extracted from $100 \mu \mathrm{L}$ media using $100 \mu \mathrm{L}$ of ultrapure water and $100 \mu \mathrm{L}$ of HPLC grade acetone. The mixture was frozen at $-80^{\circ} \mathrm{C}$ for one hour, vortexed for 60 seconds and centrifuged at $13000 \mathrm{rpm}$ for 30 minutes. The supernatant was transferred into a 13 inche glass test tube on ice and dried under nitrogen. Glutamate was converted to its N-trifluoroacetyl-n-butyl derivative by adding $200 \mu \mathrm{L}$ 3.0 M HCL in n-Butanol (Regis Chemical. Company, Chicago, IL) and incubating the mixture at $100^{\circ} \mathrm{C}$ for 1 hour. Samples were then treated with $100 \mu \mathrm{L}$ dichloromethane and 25 $\mu \mathrm{L}$ trifluoroacetic anhydride (Sigma-Aldrich) at room temperature for
20 minutes and dried under nitrogen. The residue was transferred into GC vials in $200 \mu \mathrm{L}$ dichloromethane. Under EI conditions, ionization of TAB-glutamate produces two fragments, m/z 198 and m/z 152, corresponding to the $\mathrm{C}_{2}-\mathrm{C}_{5}$ and $\mathrm{C}_{2}-\mathrm{C}_{4}$ fragments of glutamate [12]. Of the $\mathrm{m} / \mathrm{z} 198$ fragment, $\mathrm{M}_{+2}{ }^{13} \mathrm{C}$ glutamate on the $\mathrm{C}_{4}-\mathrm{C}_{5}$ carbon positions reflects pyruvate dehydrogenase activity and hence oxidative phosphorylation (catabolic use of glucose) while $\mathrm{M}_{+1}{ }^{13} \mathrm{C}$ glutamate reflects lactate and pyruvate cycling and turnover.

\section{Quantitative metabolite analysis}

Media and cell pellet metabolic products were quantitated and compared by integrated peak area values under corresponding total ion current (TIC) ID logs as determined by retention times in the selected ion monitoring mode measured by blinded spectra processing personnel (see acknowledgments). Average peak width values were less than 5 seconds (ChemStation Integrator, Agilent, and Palo Alto, CA) using identical injection volume, solvent strength and split ratios with that of natural ${ }^{13} \mathrm{C}$ labeled external chromatographic standards. Concentration dependent integrated chromatographic TIC areas are displayed as arbitrary values of metabolite concentration among the control-, glucose- and fructose-treated groups $[4,6]$.

\section{Statistical analysis}

Data are presented as arithmetic mean (average) plus standard deviation $(x+S D)$ of three independent observations using three independent integration results with background subtraction of the natural labeled ${ }^{13} \mathrm{C}$ standard and its derivatizing agent. Two-tailed independent sample " $\mathrm{t}$ "-test (Student's t-test) was used and probability values of less than 0.05 with $95 \%$ confidence intervals were considered to indicate true differences in metabolite flux results after the added glucose and fructose treatments of HepG2 cells.

\section{Results}

\section{HepG2 cells oxidize glucose at lower rates in the presence of fructose}

To compare glucose and fructose derived acetate oxidation in the TCA cycle in excess of other substrates we determined the ratio of ${ }^{12} \mathrm{CO}_{2}$ 's replacement with ${ }^{13} \mathrm{CO}_{2}$ in the culture media following the addition of $5 \mathrm{mM}$ glucose or fructose to a $4.5 \mathrm{mM}$ baseline glucose containing $10 \%\left[1,2-{ }^{13} \mathrm{C}_{2}\right]$-D-glucose tracer $(0.5 \mathrm{mM})$. This enabled us to analyze continuous substrate and product labeling for 72 hours in the HepG2 cell cultures. As depicted in Figure $1 \mathrm{~A},{ }^{13} \mathrm{CO}_{2}$ delta values were similar in culture media derived from $5 \mathrm{mM}$ glucose- $(5.78(\mathrm{SD}=0.11))$ and $10 \mathrm{mM}$ glucose- $(5.95(\mathrm{SD}=0.65))$ treated cells indicating that addition of $5 \mathrm{mM}$ glucose did not affect the ratio of complete glucosederived acetate oxidation to that of ${ }^{12} \mathrm{C}$ labeled substrates. In contrast, addition of $5 \mathrm{mM}$ fructose significantly decreased ${ }^{13} \mathrm{CO}_{2}$ Delta to 4.61 $(\mathrm{SD}=0.37)$ by its contribution to TCA cycle citrate as the unlabeled acetate/oxaloacetate source (Figure 1A). Carbon dioxide production was maintained in the presence of fructose based on the $>10 \mathrm{X}_{10}{ }^{6} \mathrm{CO}_{2}$ chromatographic abundance (not shown).

Fructose enters the TCA cycle and decreases glutamate output while maintaining pyruvate dehydrogenase and pyruvate carboxylase flux ratios for pyruvate's entry into the cycle in HepG2 cells

Media glutamate, which is synthesized via citrate, isocitrate and ketoglutarate ( $\alpha$ ), completely equilibrated with tracer glucose after 72 hours culture as demonstrated by the ${ }^{13} \mathrm{C}$ labeled fractions in the 

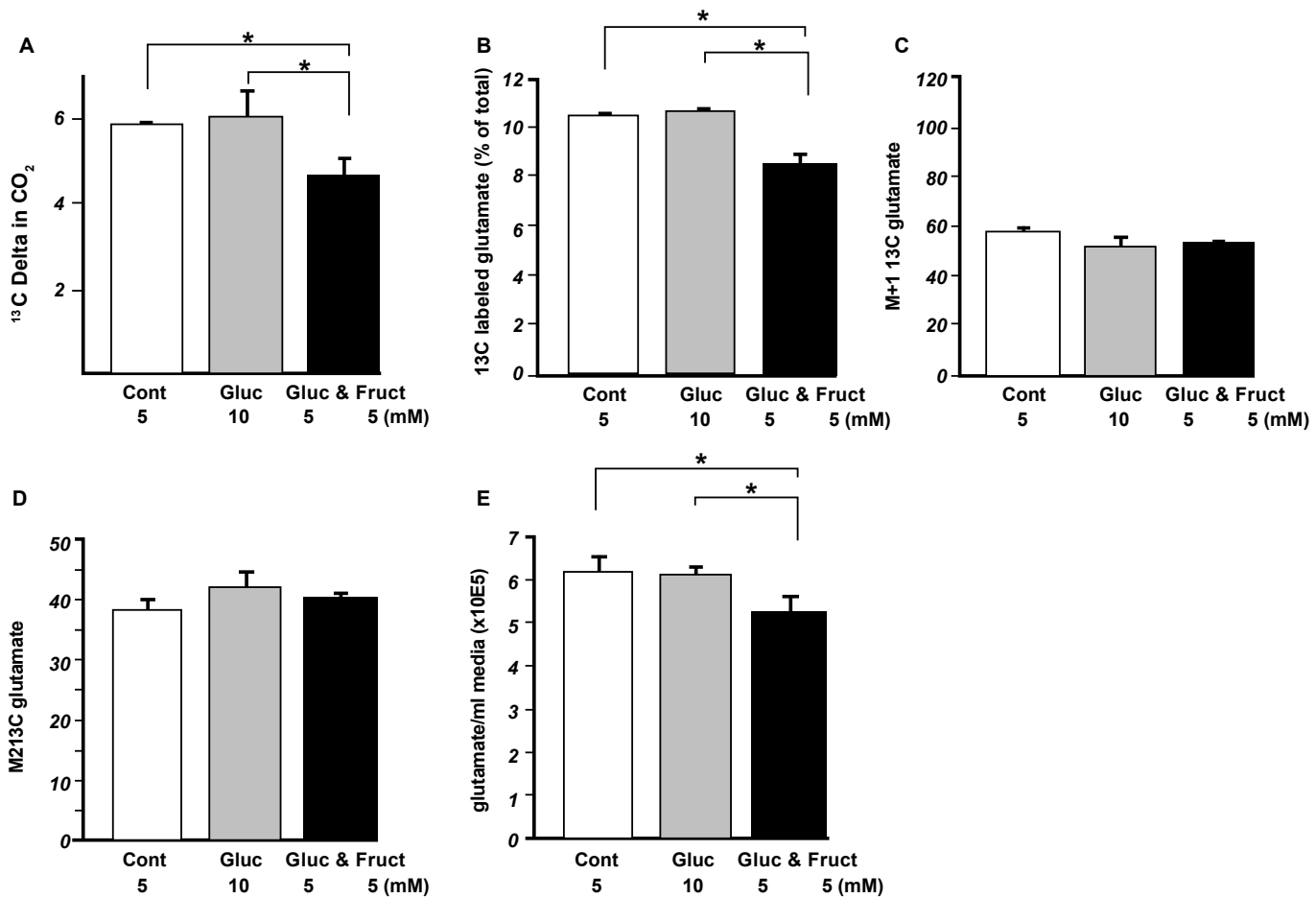

Figure 1: TCA cycle's adaptation in HepG2 cells following glucose- or fructose- treatment. Glucose (Gluc; 5 mM, middle dark bars) or fructose (Fruct; 5 mM, dark bars) was added to the baseline $4.5 \mathrm{mM}$ glucose (Cont; $4.5 \mathrm{mM}$ glucose, white bars). Ten percent $(0.5 \mathrm{mM})$ glucose was supplied in the form of [1,2-13 $\left.\mathrm{C}_{2}\right]$-D-glucose as the single metabolic tracer in each culture and replaced every $24-\mathrm{h}$ for a total of 72 hours culture. A, Complete glucose oxidation ${ }^{13} \mathrm{CO}_{2}$. Delta, which is the excess ${ }^{13} \mathrm{C}$ in released $\mathrm{CO}_{2}$ from HepG2 cells; $\mathbf{B},{ }^{13} \mathrm{C}$ labeled glutamate fraction as percent of total unlabeled glutamate in the media; $\mathbf{C}, \mathrm{Media}$ glutamate $\mathrm{M}+1 \Sigma \mu_{\mathrm{x} 2-\mathrm{x} 5}$ (one ${ }^{13} \mathrm{C}$ substitution, $\mathrm{m} / \mathrm{z} 198$ fragment, electron impact ionization) of its ${ }^{13} \mathrm{C}$ labeled fraction; $\mathbf{D}$, Media glutamate $\mathrm{M}+2 \Sigma \mu_{\mathrm{x} 2-x 5}$ (two ${ }^{13} \mathrm{C}$ substitutions, $\mathrm{m} / \mathrm{z} 198$ fragment, electron impact ionization) of its ${ }^{13} \mathrm{C}$ labeled fraction; $\mathrm{E}$, Media glutamate concentrations as integrated chromatographic peak area (arbitrary values); ( $\mathrm{n}=3$; ${ }^{*} \mathrm{p}<0.05$ ).

$5 \mathrm{mM}$ glucose control $(10.4(\mathrm{SD}=0.27))$ and $10 \mathrm{mM}$ glucose- $(10.6$ $(\mathrm{SD}=0.15))$ treated HepG2 cell derived culture media, respectively (Figure 1B). However, when $5 \mathrm{mM}$ fructose was added to the $5 \mathrm{mM}$ control glucose concentration, the ${ }^{13} \mathrm{C}$ labeled media glutamate fraction was reduced to $8.4(\mathrm{SD}=0.46)$ (Figure $1 \mathrm{~B})$. Examination of the positions of ${ }^{13} \mathrm{C}$ labeling in media glutamate revealed that positional ${ }^{13} \mathrm{C}$ labeling was very similar at both the $\mathrm{M}+1$ (one ${ }^{13} \mathrm{C}$ substitution, $\mathrm{m} / \mathrm{z} 198\left(\mathrm{C}_{2}\right.$ $\mathrm{C}_{5}$ ) fragment, reflecting lactate and pyruvate cycling and turnover) and $\mathrm{M}+2$ (two ${ }^{13} \mathrm{C}$ substitutions, $\mathrm{m} / \mathrm{z} 198\left(\mathrm{C}_{2}-\mathrm{C}_{5}\right.$ ) fragment, reflecting pyruvate dehydrogenase activity and hence oxidative phosphorylation) positions among the groups ( $5 \mathrm{mM}$ glucose control: $\mathrm{M}+1,56.57 \%$ $(\mathrm{SD}=2.81) ; \mathrm{M}+2,38.36 \%$ ( $\mathrm{SD}=1.51) ; 5 \mathrm{mM}$ added glucose: $\mathrm{M}+1$, $52.12 \%(\mathrm{SD}=3.62) ; \mathrm{M}+2,42.23 \%(\mathrm{SD}=2.36)$ and $5 \mathrm{mM}$ added fructose: $\mathrm{M}+1,53.12 \%(\mathrm{SD}=1.84) ; \mathrm{M}+239.99 \%(\mathrm{SD}=1.09)$ ), respectively (Figure $1 \mathrm{C}$ and $1 \mathrm{D})$. Glutamate concentrations, measured by the integrated peak area of the parent $\mathrm{m} / \mathrm{z} 198$ ion peak were $616467(\mathrm{SD}=40623)$ arbitrary units (AU) in control-, 609141 (SD=18586) AU in $5 \mathrm{mM}$ added glucose- and 527595 ( $\mathrm{SD}=33211)$ AU in added fructose-treated HepG2 cells (Figure 1E). These results indicate a significant decrease in glutamate synthesis and release from HepG2 cells after fructose treatment in comparison with the $5 \mathrm{mM}$ glucose control and $10 \mathrm{mM}$ glucose-treated cells $(\mathrm{p}<0.01)$.

Fructose maintains high oxidative pentose cycle flux, decreases lactate ${ }^{13} \mathrm{C}$ labeling from glucose and impairs lactate efflux from HepG2 cells

Media lactate synthesized directly from glucose via glycolysis with $\mathrm{M}+2{ }^{13} \mathrm{C}$ and indirectly from pentose via the oxidative branch of the pentose cycle (PPC) followed by recycling into glycolysis by transketolase and transaldolase with $\mathrm{M}+1{ }^{13} \mathrm{C}$ (see below) partially equilibrated with tracer glucose after 72 hours culture (Control, $3.34 \%(\mathrm{SD}=0.71)$ ). Increasing glucose concentrations by two-fold to $10 \mathrm{mM}$ resulted in a $\sim 1.5$ fold increase in released ${ }^{13} \mathrm{C}$ labeled lactate (5.47\% (SD-0.62) (Figure 2A). In contrast, addition of $5 \mathrm{mM}$ fructose reduced the ${ }^{13} \mathrm{C}$ labeled lactate fraction to $2.96 \%$ ( $\mathrm{SD}=0.69$ ) (Figure 2A). Examination of the ${ }^{13} \mathrm{C}$ labeled media lactic acid fractions' demonstrated that positional ${ }^{13} \mathrm{C}$ labeling of lactate at the $\mathrm{M}_{+1}$ position (one ${ }^{13} \mathrm{C}$ substitution, $\mathrm{m} / \mathrm{z} 328\left(\mathrm{C}_{1}-\mathrm{C}_{3}\right)$, reflecting recycled lactate through the pentose cycle) $28.67 \%(S D=5.30)$ and $M+2$ position (two ${ }^{13} \mathrm{C}$ substitutions, $\mathrm{m} / \mathrm{z} 328\left(\mathrm{C}_{1}-\mathrm{C}_{3}\right)$ reflecting lactate produced by the Embden-Myerhof-Parnas pathway) $65.49 \%(\mathrm{SD}=4.92)$ was similar in controls and not significantly altered by addition of $5 \mathrm{mM}$ glucose $\left(\mathrm{M}_{+1}, 48.13 \%(\mathrm{SD}=3.44) ; \mathrm{M}_{+2}, 47.67 \%(\mathrm{SD}=3.13)\right)$ or fructose $\left(\mathrm{M}_{+1}\right.$, $48.42 \%(\mathrm{SD}=3.32) ; \mathrm{M}_{+2} 47.44 \%(\mathrm{SD}=3.01)$ ) (Figure 2B and 2C). Pentose cycle (G6PDH) flux relative to glycolysis, also known as the "NADPH yielding direct glucose oxidizing pentose cycle reaction" was similarly increased to $25.23 \%(\mathrm{SD}=2.55)$ and $25.12 \%(\mathrm{SD}=2.64)$ in both glucoseand fructose-treated cells compared to control (13.48\% ( $\mathrm{SD}=2.99)$ ). This indicates that the number of glucose molecules entering direct oxidation doubled following glucose- and fructose-treatment. As each glucose molecules yields two reduced NADP molecules via direct oxidation of its first carbon, this generates NADPH in quadruple molar quantities, which serves as the reducing equivalent for fatty acid synthesis (Figure 2D). Triose futile cycling was relatively low in all treatments as indicated by the less than $5 \% \mathrm{M}_{+3}{ }^{13} \mathrm{C}$ lactate fraction (Figure 2E). Lactate concentrations, measured by the integrated peak 

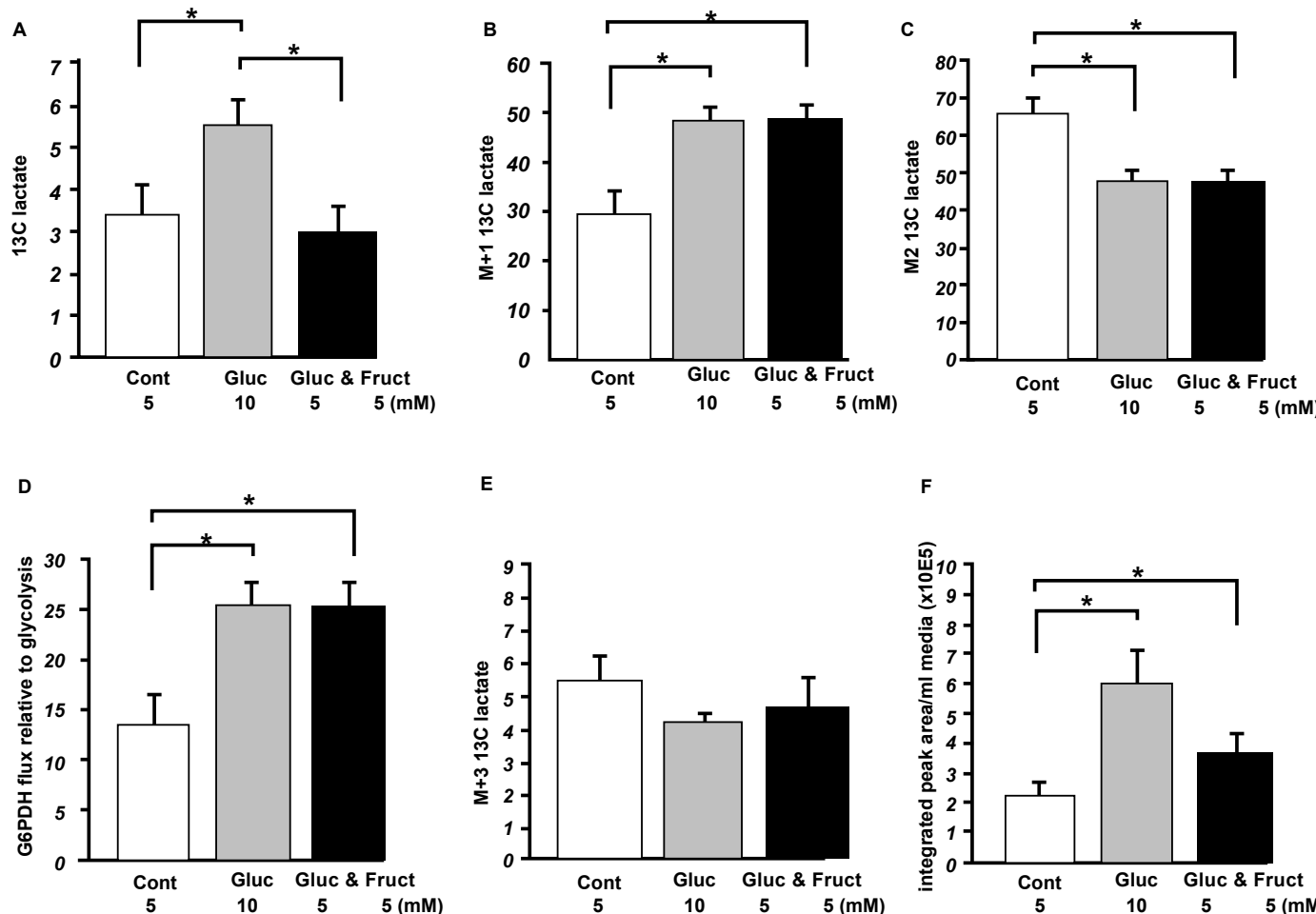

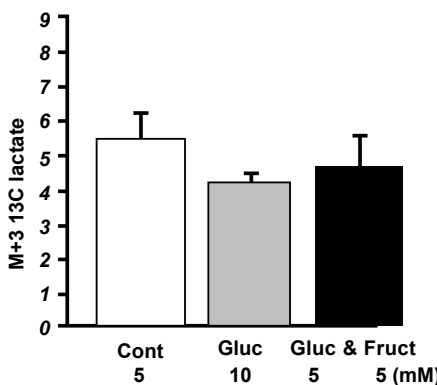

$\mathbf{F}$

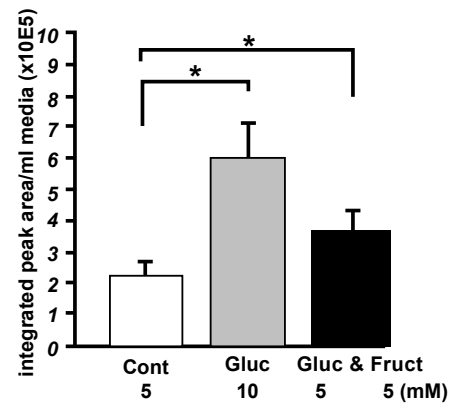

Figure 2: Adaptation via glycolysis and the pentose cycle of HepG2 cells to glucose or fructose treatment. Glucose (Gluc; 5 mM, middle dark bars) or fructose (Fruct; $5 \mathrm{mM}$, dark bars) was added to the baseline $4.5 \mathrm{mM}$ glucose (Cont; $4.5 \mathrm{mM}$ glucose, white bars). Ten percent (0.5 mM) glucose was supplied in the form of $\left[1,2-{ }^{13} \mathrm{C}_{2}\right]$-D-glucose as the single metabolic tracer in each culture and replaced every $24-\mathrm{h}$ for a total of 72 hours culture. A, ${ }^{13} \mathrm{C}$ labeled lactate fraction as percent of total unlabeled lactate in the media; $\mathbf{B}$, Media lactate $\mathrm{M}+1 \sum \mathrm{m}_{\mathrm{C1}-\mathrm{C} 3}$ (one ${ }^{13} \mathrm{C}$ substitution, $\mathrm{m} / \mathrm{z} 328$ ion, chemical ionization) of its ${ }^{13} \mathrm{C}$ labeled fraction; $\mathbf{C}$, Media lactate $\mathrm{M}+2 \Sigma \mathrm{m}$ (two ${ }^{13} \mathrm{C}$ substitutions, $\mathrm{m} / \mathrm{z} 328$ fragment, chemical ionization) of its ${ }^{13} \mathrm{C}$ labeled fraction; D, Pentose cycle flux relative to glycolysis via glucose-6Pdehydrogenase (G6PDH), transketolase and transaldoase; $\mathbf{E}$ Triose futile cycling into $\mathrm{M}+3 \Sigma \mu_{x_{1-x} x_{3}}$ (two ${ }^{13} \mathrm{C}$ substitutions, $\mathrm{m} / \mathrm{z} 328$ fragment, chemical ionization) of its ${ }^{13} \mathrm{C}$ labeled fraction; F, Media lactate concentrations as integrated chromatographic peak area (arbitrary values); $\left(n=3 ;{ }^{*} p<0.05\right)$

area of the parent $\mathrm{m} / \mathrm{z} 328$ ion peak increased significantly following glucose-treatment $(593279(\mathrm{SD}=118124))$ compared to control(217388 (SD=51477)) and fructose-treated cells (363956 (SD=68570)), respectively (Figure 1F), in keeping increased lactate synthesis and release from glucose-treated HepG2 cells.

Fructose contributes directly to nucleotide ribose synthesis and recycles glucose-derived glyceraldehyde-3P via transketolase in HepG2 cells

Cell pellet ribose is the backbone pentose sugar of nucleotide synthesis and is produced either directly from glucose via the oxidative branch of the pentose cycle with $\mathrm{M}+1{ }^{13} \mathrm{C}$ or indirectly from fructose by transketolase with $\mathrm{M}+2{ }^{13} \mathrm{C}$ (sees below). Direct and indirect ribose synthesis partially equilibrated with tracer glucose after 72 hours culture as shown by the $4.69 \%(\mathrm{SD}=0.14)$ and $5.73 \%(\mathrm{SD}=0.62){ }^{13} \mathrm{C}$ labeled $\mathrm{C}_{1}$ $\mathrm{C}_{4}$ (top, $\mathrm{m} / \mathrm{z} 242$ ) fractions in the $5 \mathrm{mM}$ control and $10 \mathrm{mM}$ glucose treated HepG2 culture media, respectively (Figure 3A). In contrast, addition of $5 \mathrm{mM}$ fructose to the $5 \mathrm{mM}$ control glucose-treated cells reduced the ${ }^{13} \mathrm{C}$ labeled ribose fraction to $4.07 \%$ ( $\mathrm{SD}=0.11$ ) (Figure $3 \mathrm{~A}$ ), indicating that the unlabeled fructose directly contributes to RNA ribose synthesis after phosphorylation as the $C_{2}(\beta)$ keto-group-donor. Examination of positional ${ }^{13} \mathrm{C}$ labeling of the ${ }^{13} \mathrm{C}$ labeled pellet ribose $\mathrm{C}_{1}-\mathrm{C}_{4}$ (top, $\mathrm{m} / \mathrm{z} 242$ ) fractions demonstrated that $89.54 \%(\mathrm{SD}=1.65)$ of control-, $79.33 \%(\mathrm{SD}=3.93)$ of $10 \mathrm{mM}$ glucose and $79.61 \%(\mathrm{SD}=0.10)$ of fructose-treated cells had one ${ }^{13} \mathrm{C}$ substitution $\left(\mathrm{M}_{+1}\right.$, one ${ }^{13} \mathrm{C}$ substitution, $\mathrm{m} / \mathrm{z} 242\left(\mathrm{C}_{1}-\mathrm{C}_{4}\right)$ reflecting the ribose fraction produced by direct oxidation of glucose or fructose through the G6PDH) and $9.31 \%$ $(\mathrm{SD}=0.81)$ control, $14.83 \%(\mathrm{SD}=1.19) 10 \mathrm{mM}$ glucose and $15.45 \%$ ( $\mathrm{SD}=1.85)$ added fructose had two ${ }^{13} \mathrm{C}$ substitutions, $(\mathrm{M}+2, \mathrm{~m} / \mathrm{z} 242$ $\left(\mathrm{C}_{1}-\mathrm{C}_{4}\right)$ pathway reflecting the fraction produced by transketolase) respectively (Figure $3 \mathrm{~B}$ and $3 \mathrm{C}$ ). Triose (glyceraldehyde-3P) recycling into ribose via transketolase increased to $76.47 \%(\mathrm{SD}=0.64)$ after glucose- and $79.83 \% \quad(\mathrm{SD}=1.26)$ following fructose-treatment, respectively, compared to $71.27 \%(S D=1.78)$ in control glucose pellets (Figure 3D). Integrated peak area of the $\mathrm{m} / \mathrm{z} 242$ ion peak was similar following control- $(5135$ (SD=1541)), glucose- $(4265(\mathrm{SD}=195))$ and fructose- $(4676(\mathrm{SD}=1246))$ treatment (not shown).

Fructose supplies acetyl-CoA for new palmitate and oleate synthesis while strongly promoting fatty acid co-release from HepG2 cells

Palmitate (C16:0) and oleate (C18:1) are abundant long chain fatty acids of triglycerides assembled by liver cells for transport. Palmitate readily incorporated the tracer glucose after 72 hours culture as shown by the chromatographic analyses of the pellets. Palmitate ${ }^{13} \mathrm{C}$ molar enrichment was $0.18(\mathrm{SD}=0.02)$ in control and $0.26(\mathrm{SD}=0.01)$ in 10 $\mathrm{mM}$ glucose-treated HepG2 cells. Addition of $5 \mathrm{mM}$ fructose reduced the ${ }^{13} \mathrm{C}$ content in palmitate to $0.21(\mathrm{SD}=0.01)$ relative to that of added glucose (Figure $4 \mathrm{~A}$ ), which indicates that unlabeled fructose-derived acetyl-CoA directly contributes to palmitate synthesis (see also below) in HepG2 cells. Interestingly, intracellular oleate also incorporated the glucose tracer more avidly as demonstrated by the $0.36(\mathrm{SD}=0.02)$ and 


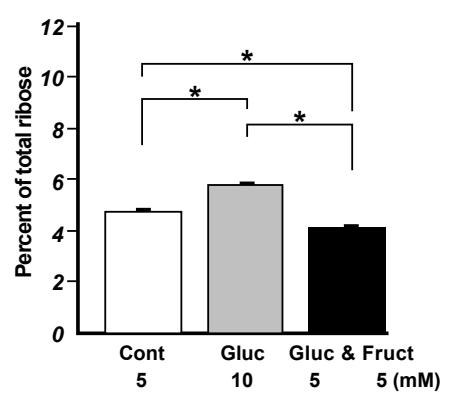

D

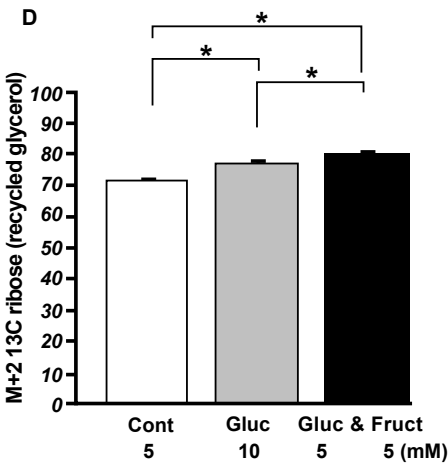

B

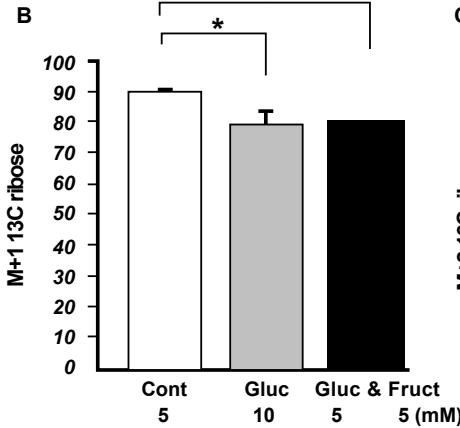

C

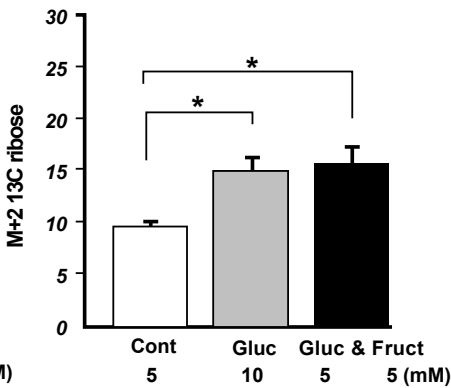

(the or fructose (Fruct; $5 \mathrm{mM}$, dark bars) was added to the baseline $4.5 \mathrm{mM}$ glucose (Cont; $4.5 \mathrm{mM}$ glucose, white bars). Ten percent (0.5 mM) glucose was supplied in the form of $\left[1,2-{ }^{13} \mathrm{C}_{2}\right]-\mathrm{D}$-glucose as the single metabolic tracer in each culture and replaced every $24-\mathrm{h}$ for a total of 72 hours culture. A, ${ }^{13} \mathrm{C}$ labeled ribose fraction as percent of total unlabeled ribose in cell pellets; $\mathbf{B}$, Pellet ribose $\mathrm{M}+1 \Sigma \mu_{x 1} \mathrm{C}$ (one ${ }^{13} \mathrm{C}$ substitution, $\mathrm{m} / \mathrm{z} 242$ ion, electron impact ionization) of its ${ }^{13} \mathrm{C}$ labeled fraction; $\mathbf{C}$ Pellet ribose $\mathrm{M}+2 \sum \mu_{\mathrm{x} 1-x_{4}}$ (two ${ }^{13} \mathrm{C}$ substitutions, $\mathrm{m} / \mathrm{z} 242$ fragment, electron impact ionization) of its ${ }^{13} \mathrm{C}$ labeled fraction; $\mathbf{D}$, Triose (glyceraldehyde-3P recycling) via transketolase as ribose as $\mathrm{M}+2 \Sigma \mu_{\mathrm{x} 3-\mathrm{x} 6}$ (two ${ }^{13} \mathrm{C}$ substitutions, $\mathrm{m} / \mathrm{z} 217$ fragment, electron impact ionization) of its ${ }^{13} \mathrm{C}$ labeled fraction ( $\mathrm{n}=3$; ${ }^{*} \mathrm{p}<0.05$ ).

$0.42(\mathrm{SD}=0.02){ }^{13} \mathrm{C}$ molar oleate enrichment in the control- and 10 $\mathrm{mM}$ glucose-treated HepG2 cells, respectively. Similar to palmitate ${ }^{13} \mathrm{C}$ enrichment, addition of $5 \mathrm{mM}$ fructose reduced ${ }^{13} \mathrm{C}$ content in oleate to $0.36(\mathrm{SD}=0.01)$ compared to $10 \mathrm{mM}$ glucose (Figure $4 \mathrm{~B})$. Release of palmitate into the culture media after 72 hours culture was similar in control $(0.17(\mathrm{SD}=0.01)$ and $10 \mathrm{mM}$ glucose groups $(0.18(\mathrm{SD}=0.007))$. In contrast, addition of $5 \mathrm{mM}$ fructose markedly reduced the ${ }^{13} \mathrm{C}$ content in released palmitate to $0.10(\mathrm{SD}=0.01)$ (Figure $4 \mathrm{C})$, which indicates that unlabeled fructose-derived acetyl-CoA significantly contributes to released palmitate synthesis in HepG2 cells. Released oleate also incorporated tracer glucose with higher intensity, showing $0.29 \%(\mathrm{SD}=0.01)$ and $0.32(\mathrm{SD}=0.02){ }^{13} \mathrm{C}$ molar enrichment in released oleate in the $5 \mathrm{mM}$ control and $10 \mathrm{mM}$ glucose treated HepG2 cells, respectively. However, addition of $5 \mathrm{mM}$ fructose resulted in reduced ${ }^{13} \mathrm{C}$ oleate content $(0.26(\mathrm{SD}=0.02))$ relative to $10 \mathrm{mM}$ glucose-treated cells (Figure $4 \mathrm{D}$ ). Intracellular fatty acid $\mathrm{M}+2$ positional ${ }^{13} \mathrm{C}$ palmitate and oleate labeling, the latter requiring pyruvate dehydrogenase activity followed by i mMediate citrate shuttling were similar in all treatment groups $\left(\mathrm{M}+2\right.$ positional ${ }^{13} \mathrm{C}$ palmitate: control; 63.71\% ( $\left.\mathrm{SD}=0.64\right), 10$ $\mathrm{mM}$ glucose; $65.80 \%(\mathrm{SD}=0.47)$ and $5 \mathrm{mM}$ fructose; $64.09 \%(\mathrm{SD}=0.72)$ and $\left(\mathrm{M}+2\right.$ positional ${ }^{13} \mathrm{C}$ oleate: control; $29.77 \%(\mathrm{SD}=1.28), 10 \mathrm{mM}$ glucose; $35.87 \%(\mathrm{SD}=0.44)$ and $5 \mathrm{mM}$ fructose; $32.28 \%(\mathrm{SD}=0.54)$ ) (not shown). Analysis of released ${ }^{13} \mathrm{C}$ labeled fatty acid fractions demonstrated increased $\mathrm{M}+2$ positional ${ }^{13} \mathrm{C}$ palmitate labeling in $10 \mathrm{mM}$ glucose-treated $(52.08 \%(\mathrm{SD}=0.64))$ compared to control(49.59\% $(\mathrm{SD}=0.32))$ and $5 \mathrm{mM}$ fructose-treated $(48.85 \%(\mathrm{SD}=2.8))$ cells (not shown) but similar $\mathrm{M}+2$ positional ${ }^{13} \mathrm{C}$ oleate labeling in all three groups (Control; 20.88\% ( $\mathrm{SD}=2.17) ; 10 \mathrm{mM}$ glucose $(22.78 \%$ $(\mathrm{SD}=2.73)$ ) and $5 \mathrm{mM}$ fructose; $16.34 \%(\mathrm{SD}=1.78)$ ) (not shown).

Our analysis also revealed that intracellular palmitate and oleate content (integrated peak area) increased following $10 \mathrm{mM}$ glucose (Palmitate: 25394 (SD=1485; Oleate: 12124 (SD=1192) in comparison to control (Palmitate: 20515 ( $\mathrm{SD}=1735$; Oleate: 11012 ( $\mathrm{SD}=1655)$. In contrast, $5 \mathrm{mM}$ fructose-treatment led to a marked reduction in intracellular palmitate and oleate levels (Palmitate: $12684(\mathrm{SD}=586)$; Oleate: $6456(\mathrm{SD}=576)$ (Figure $4 \mathrm{E}$ and $4 \mathrm{~F})$. In marked contrast to intracellular palmitate and oleate levels, released palmitate and oleate contents (integrated peak areas) were significantly increased after fructose treatment (Figure 4G and $4 \mathrm{H}$ ) (Palmitate: $4613(\mathrm{SD}=580)$; Oleate: 3954 ( $\mathrm{SD}=708)$ in comparison to $10 \mathrm{mM}$ glucose- (Palmitate: 2009 (SD=80); Oleate: $949(\mathrm{SD}=77)$ and control- (Palmitate: 2340 ( $\mathrm{SD}=347)$; Oleate: $1068(\mathrm{SD}=307)$ treated HepG2 cells. Furthermore, intracellular palmitate production by de novo synthesis via citrate formation, its shuttling and fatty acid synthase (FAS) (Figure 4I) were also increased in glucose- $63.09 \%(\mathrm{SD}=0.32)$ and fructose- $56.12 \%$ $(\mathrm{SD}=3.40)$ treated cells compared to control $(44.6 \%(\mathrm{SD}=2.36))$. There was also a significant decrease in glucose-derived acetyl-CoA contribution to palmitate in fructose- $(1.60 \%(\mathrm{SD}=0.1)$ compared to control- $(18.2 \%(\mathrm{SD}=0.5))$ and $10 \mathrm{mM}$ glucose- $(18.8 \%(\mathrm{SD}=0.5))$ treated cells, quantitated as the fraction of total acetyl-CoA from all sources (Figure 4J).

\section{Discussion}

The human hepatocellular carcinoma HepG2 cell was selected for 

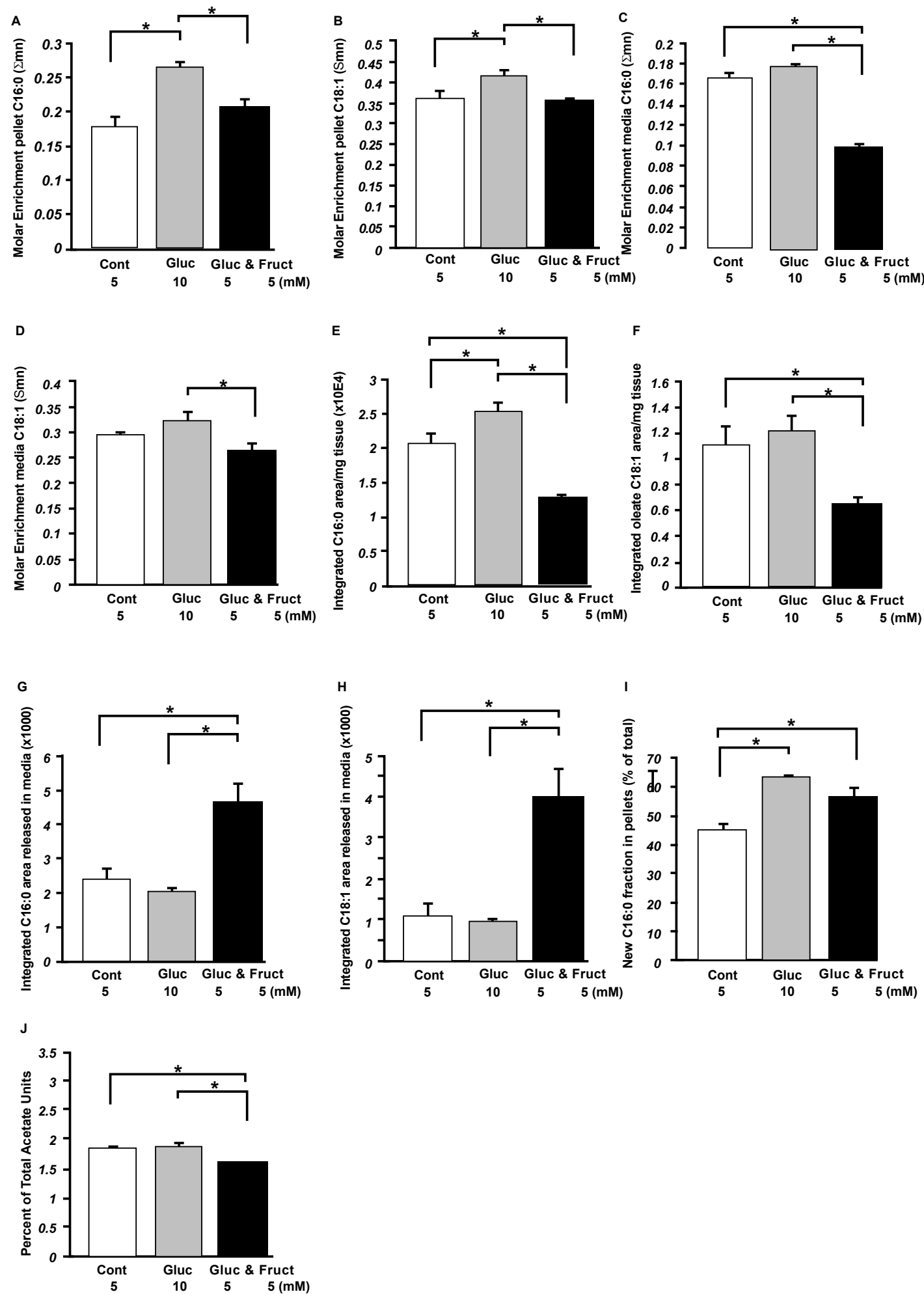

Figure 4: Adaptation of fatty acid palmitate (C16:0) and oleate (C18:1) synthesis and transport to glucose or fructose treatment in HepG2 cells. Glucose (Gluc; $5 \mathrm{mM}$, middle dark bars) or fructose (Fruct; $5 \mathrm{mM}$, dark bars) was added to the baseline $4.5 \mathrm{mM}$ glucose (Cont; $4.5 \mathrm{mM}$ glucose, white bars). Ten percent ( 0.5 $\mathrm{mM}$ ) glucose was supplied in the form of $\left[1,2-{ }^{13} \mathrm{C}_{2}\right]-\mathrm{D}$-glucose as the single metabolic tracer in each culture and replaced every $24-\mathrm{h}$ for a total of 72 hours culture. A

${ }^{13} \mathrm{C}$ content $(\Sigma \mu)$ of palmitate and $\mathbf{B}$, oleate in cell pellets; $\mathbf{C},{ }^{13} \mathrm{C}$ content $(\Sigma \mathrm{m})$ of palmitate and $\mathbf{D}$, oleate, respectively, in culture media; $\mathbf{E}$, Cell pellet palmitate and $\mathbf{F}$, oleate concentrations; G, Media palmitate and $\mathbf{H}$, oleate concentrations as integrated chromatographic peak area (arbitrary values); I, Intracellular palmitate via de novo synthesis via citrate formation, its shuttling and FAS and $\mathbf{J}$, glucose-derived acetyl-CoA contribution to intracellular palmitate synthesis (percent of total acetylCoA from all sources); ( $\left.n=3 ;{ }^{*} p<0.05\right)$. 
our studies based on similarities with isolated human hepatocytes. These features include their ability to 1) metabolize fructose to two carbon organic acids [13], 2) maintain most primary liver cell functions including ureagenesis, glucuronidation, sulfation and oxidation [14], 3) respond to food pro-mutagens in a similar manner to human liver cells [15] and 4) exhibit nicotinic acid and nicotinamide transport (cofactors for oxidative decarboxylation and direct glucose oxidation) which is unaffected by related organic anions such as lactate, acetate, butyrate, succinate or citrate availability and influx [16].

Recent studies have reported mean circulating serum fructose concentrations around $1.9+/-0.4 \mathrm{mM}$ in unprocessed serum samples from fasting healthy volunteers [17] or $0.046+/-0.025 \mathrm{mM}$ after separation of hemoglobin from plasma [18]. Using enzymatic and chromatographic assays, we demonstrated that plasma fructose levels rose rapidly to $16.3+/-1.2 \mathrm{mM} 15$ minutes after ingestion of a fructose and glucose-containing beverage. We therefore chose to examine combination treatment with glucose and fructose concentrations equivalent to $\sim 10 \mathrm{mM}$ total carbohydrate as we believe this concentration is reflective of portal sugar concentrations following ingestion of high refined carbohydrate quantities easily attained from western diets.

Although it is known that short-term fructose administration increases circulating VLDL triacylglycerols by about 58\% in human subjects [19], the exact mechanisms involved remain speculative [2]. Based on this study it is evident that fructose maintains a high glucose direct oxidation rate via the oxidative branch of the pentose cycle, very similar to that of added glucose, while fructose itself does not undergo effective direct oxidation. On the other hand fructose profoundly alters intermediary metabolism and impairs the metabolism of glucose in a competitive manner in a similar way to that seen in the Randle cycle $[20,21]$. As the Randle cycle highlights competition between glucose and fatty acids for their oxidation in muscle and adipose tissue [22], our study, for the first time, demonstrates the same effect of fructose in hepatic cells. Our study demonstrates fructose-mediated impaired glucose oxidative decarboxylation as evidenced by our observed reduction in both $13 \mathrm{CO}_{2}$ and glutamate while maintaining overall $\mathrm{CO}_{2}$ production following fructose- treatment. The results reveal a new dimension of metabolic control whereby the nutrient, fructose, modifies hepatic metabolism of another sugar in a similar way to fatty acids. Although it has been shown that the utilization of one nutrient (fatty acid) inhibits the use of the other (glucose) directly in isolated heart and skeletal muscle preparations [21], our report is the first we are aware of that demonstrates the same interaction between two dietary sugars. The glucose-fructose cycle is thus a novel biochemical phenomenon that is determined by fructose availability and controls fuel selection and product disposal via adaptation to refined sugar supply and demand in cells. It is likely that other factors such as hormones that act to control circulating substrate concentrations play a role in the interplay between glucose and fructose and this will require clarification in additional in vivo studies.

Our glucose tracer studies indicate that the manner by which fructose impairs glucose metabolism does not include the proposed mechanisms whereby high concentrations of fatty acids inhibit glucose utilization, including inhibition of glucose transport and/ or phosphorylation or reduced activity of pyruvate dehydrogenase (PDH) [20]. This is supported by the similar positional ${ }^{13} \mathrm{C}$ labeling in glutamate in the control and fructose-treated groups and the identical positional ${ }^{13} \mathrm{C}$ labeling in lactate following $10 \mathrm{mM}$ glucose- and fructose-treatments in our study. This finding indicates that glucose and fat and glucose and fructose may interact via distinct mechanisms.
The mechanisms by which fructose alters glucose metabolism in HepG2 cells are consistent with three unexpected results. Firstly, fructose resulted in a striking, 2-3- fold increase in palmitate and oleate co-release, which is typical and necessary in liver cells for effective triglyceride assembly and transport, as palmitate and oleate are transported together in VLDL. Secondly, the synthesis pathways of released palmitate and oleate are very different from intracellular palmitate and oleate synthesis. In particular, released fatty acids contained less $\mathrm{M}_{+2}$ derived from glucose and this is a very specific marker of increased glucose decarboxylation via the oxidative and direct pathways and the subsequent channeling of acetyl-CoA product to the fatty acid synthase complex. The exact reason for our observed difference in intracellular versus secreted oleate labeling is unclear but we speculate may involve different metabolite compartmentalization. Thirdly, hepatoma cells retain less palmitate and oleate after fructose treatment, which indicates that fatty acid accumulation in fructoseinduced steatosis may exclude palmitate and oleate accumulation.

In conclusion, it is evident that fructose impairs hepatic HepG2 cell glucose metabolism as profoundly as that observed with fatty acid administration in the Randle cycle. Our study puts in perspective the finding that although a high combination fructose and fatty acid diet had additive effects on intrahepatocellular lipid deposition, the diet exhibited neutralizing effects on VLDL triglyceride release [19]. Our study also demonstrates that although fructose stimulates hepatic VLDL triacylglycerol secretion it also depletes two important selective fatty acid pools, namely that of palmitate and oleate, whereby dietderived long chain saturated fatty acids may be stored. These diverse, yet interfering mechanisms will shed further light on the complexities involved in hidden disease phenotypes and may have relevance for population scale obesity. Additionally, we anticipate that they will trigger additional tracer substrate guided investigations in the field to better understand the mechanisms by which dietary nutrients interact to mediate human disease.

\section{Acknowledgements}

This research was supported by NIH grant CA123273 (A.P.H.), The Hirshberg Foundation and the UCLA Jonsson Cancer Center. We thank Ferenc Nádudvari for help preparing the graphic abstract for the paper, Aniko Geri for spectra processing Csaba Geri for the event-driven and integrated data loading programs as well as their compilation from Visual Basic to the Excel (Microsoft 2003) environment and Maria Csikos for generating the graphic output files used in this article in PowerPoint (Microsoft 2007).

\section{References}

1. Stanhope KL, Havel PJ (2009) Fructose consumption: considerations for future research on its effects on adipose distribution, lipid metabolism, and insulin sensitivity in humans. J Nutr. 139: 1236S-1241S

2. Spruss A, Bergheim I (2009) Dietary fructose and intestinal barrier: potentia risk factor in the pathogenesis of nonalcoholic fatty liver disease. J Nutr Biochem 20: 657-662.

3. Metallo CM, Walther JL, Stephanopoulos G (2009) Evaluation of $13 \mathrm{C}$ isotopic tracers for metabolic flux analysis in mammalian cells. J Biotechnol 144: 167 174.

4. Paul Lee WN, Wahjudi PN, Xu J, Go VL (2010) Tracer-based metabolomics: Concepts and practices. Clin Biochem 43: 1269-1277.

5. Dickens F, Glock Ge (1950) Direct oxidation of glucose-6-phosphate by animal tissues. Nature 166: 33.

6. Liu H, Huang D, McArthur DL, Boros LG, Nissen N, et al. (2010) Fructose induces transketolase flux to promote pancreatic cancer growth. Cancer Res 70: 6368-6376.

7. Lee WN, Boros LG, Puigjaner J, Bassilian S, Lim S, et al. (1998) Mass isotopomer study of nonoxidative pathways of the pentose cycle with $\left[1,2-13 \mathrm{C}_{2}\right]$ glucose. Am J Physiol 274: E843-51. 
Citation: Boros LG, Huang D, Heaney AP (2012) Fructose Drives Glucose via Direct Oxidation and Promotes Palmitate/Oleate Co-Release from Hepg2 Cells: Relevance with the Randle Cycle. Metabolomics 2:107. doi:10.4172/2153-0769.1000107

8. Hellerstein MK, Neese RA (1992) Mass isotopomer distribution analysis: a technique for measuring biosynthesis and turnover of polymers. Am J Physio 263: E988-1001.

9. Follstad BD, Stephanopoulos G (1998) Effect of reversible reactions on isotope label redistribution: analysis of the pentose phosphate pathway. Eur J Biochem 252: 360-371.

10. Boros LG, Puigjaner J, Cascante M, Lee WN, Brandes JL, et al. (1997) Oxythiamine and dehydroepianrosterone inhibit the nonoxidative synthesis of ribose and tumor cell proliferation. Cancer Res 57: 4242-4248.

11. Mizumori M, Meyerowitz J, Takeuchi T, Lim S, Lee P, et al. (2006) Epithelia carbonic anhydrases facilitate $\mathrm{PCO} 2$ and $\mathrm{pH}$ regulation in rat duodenal mucosa. J Physiol 573: 827-842.

12. Bartnik BL, Hovda DA, Lee PW (2007) Glucose metabolism after traumatic brain injury: estimation of pyruvate carboxylase and pyruvate dehydrogenase flux by mass isotopomer analysis. J Neurotrauma 24: 181-194.

13. Knight J, Holmes RP (2008) Fructose metabolism to two carbon acids in HepG2 cells. The FASEB Journal 22: 9499.

14. Nyberg SL, Remmel RP, Mann HJ, Peshwa MV, Hu WS, et al. (1994) Primary hepatocytes outperform Hep G2 cells as the source of biotransformation functions in a bioartificial liver. Ann Surg 220: 59-67.

15. Wilkening S, Stahl F, Bader A (2003) Comparison of primary human hepatocytes and hepatoma cell line Hepg2 with regard to their biotransformation properties. Drug Metab Dispos 31: 1035-1042.
16. Said HM, Nabokina SM, Balamurugan K, Mohammed ZM, Urbina C, et al (2007) Mechanism of nicotinic acid transport in human liver cells: experiments with HepG2 cells and primary hepatocytes. Am J Physiol Cell Physiol 293: C1773-1778

17. Hui H, Huang D, McArthur D, Nissen N, Boros LG, et al. (2009) Direct spectrophotometric determination of serum fructose in pancreatic cancer patients. Pancrea 38: 706-712.

18. Wahjudi PN, Patterson ME, Lim S, Yee JK, Mao CS, et al. (2010) Measurement of glucose and fructose in clinical samples using gas chromatography/mass spectrometry. Clin Biochem 43: 198-207.

19. Sobrecases H, Lê KA, Bortolotti M, Schneiter P, Ith M, et al. (2010) Effects of short-term overfeeding with fructose, fat and fructose plus fat on plasma and hepatic lipids in healthy men. Diabetes Metab 36: 244-246.

20. Frayn KN (2003) The glucose-fatty acid cycle: a physiological perspective. In: Regulation in Metabolism Group Colloquium, Edited by Titheradge MA, Ferre P. $679^{\text {th }}$ Meeting of the Biochemical Society. University of Essex, Colchester 115-1119.

21. Randle PJ, Garland PB, Hales CN, Newsholme EA (1963) The glucose fattyacid cycle. Its role in insulin sensitivity and the metabolic disturbances of diabetes mellitus. Lancet 1: 785-789.

22. Hue L, Taegtmeyer H (2009) The Randle cycle revisited: a new head for an old hat. Am J Physiol Endocrinol Metab 297: E578-E591. 